\title{
INCENTIVE MECHANISM DESIGN AND SIMULATION OF EMISSION TRADING BASED ON MARKET MAKER SYSTEM
}

\author{
LI, Q. H. ${ }^{*}$ - LI, Y. S. - LI, L. F. - WANG, Y. X. \\ School of Economics and Management, Beijing Jiaotong University, 100044, Beijing, China \\ (phone/fax: +86-010-5168-5230) \\ *Corresponding author \\ e-mail:16113137@bjtu.edu.cn; phone: +86-135-1102-2452
}

(Received $8^{\text {th }}$ Mar 2019; accepted $1^{\text {st }}$ May 2019)

\begin{abstract}
Through model hypothesis and simulation experiment method, this paper demonstrates the behaviour choice of the market maker and emission discharge enterprise after a certain long-term operation with market maker mechanism in the emission trading market under certain pre-defined conditions. Each subject's and overall utility are explored. After analysing the impact of market demand and price difference on market maker trading, the relevant suggestions for introducing the market maker mechanism in the emissions trading market are given.
\end{abstract}

Keywords: emission discharge, market maker mechanism, dynamic system, market fluctuations, environment protection

\section{Introduction}

The management of emission rights is an inevitable way to create a harmonious living environment, and it is also a serious issue facing all countries in the world $(\mathrm{Du}$, et al., 2018). International experience shows that emissions trading mechanisms can maximize social benefits while protecting wealth creation, compared to administrative orders and taxation. In a market where market makers participate, the spread (the difference between the asking price and the bid) is not only the price that the market maker provides, which is adjusted according to the change of the market maker's optimal choice (Shen and Starr, 2002), but also a major indicator of the liquidity provided by market makers. It is generally believed that the greater the spread, the greater the risk of holding inventory and thus the lower liquidity (Tarun and Richard, 2001), and vice versa. There are two main theories about the interpretation of the price difference: inventory control theory and reverse selection theory.

The starting point of the inventory control theory is that the market maker must have a certain inventory reserve in order to make the market. Due to the changes in market factors such as interest rates, the market makers will be affected by the uncertainty of the inventory value changes (Gong, et al., 2018). Therefore, the market makers will adjust the ask price and bid price in the quotation to balance inventory risk. The transaction cost problem involved in the spread can be understood by considering the analysis of a neglected problem "foreseeable transaction immediateness" (Demsetz, 1968).

The inverse selection model assumes that there is information asymmetry in the market. There is a market maker and two types of traders in the market: liquid traders and traders with information advantages. Market makers optimize their offers to get the most benefit, that is, by setting a spread to maximize Gains earned by liquidity traders and losses suffered by information advantage traders (Glosten and Milgrom, 1985; Kyle, 1985; Bondarenko, 2001; Calcagno and Lovo, 2006; Zhang and Li, 2011). 
From the monopolistic of market makers and the impact of competition on the market, centralized model research shows that the monopolistic expert system on the New York Stock Exchange enables market makers to enhance social welfare because in the scattered market, it partially internalizes the externalities of the spread (Miao, 2006).

From the transparency aspect of information, researchers examined the price display effect in the market maker market and found that in the opaque market, the open spread is large and trading volume is low due to higher search costs, but higher search costs lead to more aggressive pricing strategies, so price discovery speeds are faster in opaque markets (Flood, et al., 1999; Bloomfield and O'Hara, 2000).

In addition, some studies have investigated the aspects of market stability, market maker financing, and locality of market makers. Financial market models were used to test the stability of market makers to the market (Zhu et al., 2009). They assumed that there are two types of investors in the market: fundamental investors and trend investors, market makers acting as liquidity providers and active investors. The research results show that when market makers actively manage their inventory to maximize profits, they do not stabilize the market; and the behavior of market makers depends on the behavior of speculators (Zhu, et al., 2009). The information advantage of local market makers is a very valuable factor in reducing transaction costs (Kedia and Zhou, 2011).

Overall, the research on the market maker system of emission trading at home and abroad is still very imperfect. The Emission trading market should play an active role in pollution control. The market mechanism needs to be improved. The market makers acting as emission trading intermediaries are one of the important components of micro market structures. To introduce market maker trading in the pilot trading phase of China, the most urgent task is to have a complete set of incentives and constraints for market makers to ensure the effectiveness of market makers' behavior. This is also the shortcoming of the current research.

\section{Methods}

Since China's emission trading market has not adopted the market maker trading system, this study uses the simulation experiment method to study the trading efficiency of market makers in the emission trading market. The experimental method is one of the main methods for researchers at home and abroad to study emissions trading. In order to reflect the transaction efficiency of the market maker's quotation, the trading system set up by the research institute contains a market maker and a number of emission discharging enterprises. The transactions of the emission discharging enterprises are carried out by the market makers, and the current emission discharge certificates cannot be stored in the conditions of next stage of transaction. Due to the need of market making, the market maker needs to balance the relationship between the current transaction income and the storage cost. under the established supervision, the emission discharge enterprises trade considering the quote of the market maker and its own emission reduction cost. Based on this, this paper explores the long-term behavioral evolution of each participant, studies the transaction efficiency of market makers' quotations in the emission discharge trading market, and provides theoretical guidance for the application of market maker quotation system in China's emissions trading practice. 
Hypothesis 1: Each trading entity adjusts its decisions based on their respective profit conditions. In the emission trading system, the amount and quotation of the emission right of the market maker is private information and the quotation setting needs the market maker's information collection of each emission enterprise. Due to the incompleteness of the information, the decision of the market maker and the emission enterprise Behaviors are adjusted only based on the information they have. Under the condition of profit maximization, the profit value can be regarded as the most credible indicator, so it is assumed that each transaction entity adjusts the decision according to their respective profit conditions.

Hypothesis 2: The spread of each period is fixed, but the market maker will adjust the ask price and bid for the next period based on the information of this period. The market makers need to make quotations during making the market. If the price difference is too large, it will damage the interests of the traders, and it is not conducive to the liquidity of the market. In order to standardize the market making behavior of market makers, it is in practice to set the price difference magnitude or upper limit. Therefore, this paper sets a fixed spread and assumes that the spread will remain the same in each period, but the market maker will adjust the bid and bid for the next period based on the information in this period. The model parameters are set as follows:

$D$ - the total market demand of the product, assuming a normal distribution;

$D_{i}$ - the market demand for the products of enterprise $i$;

$A P$ - the asking price of the market maker;

$B P$ - the bid of the market maker;

$N$ - the number of emission enterprises;

$R_{i}$ - the product profit obtained by use of each unit of the emission certificate;

$L$ - the total amount of emission permits available for distribution;

$L_{i}$ - the number of emission control certificates assigned by each company;

$C_{i}$ - the cost of abatement of enterprise i, assumed to follow a normal distribution;

$Q_{i}$ - the trading volume of the emission certificate;

$Q_{1 i}$ - the amount of sales of emission control certificates;

$Q_{2 i}$ - the purchase amount of the pollutant discharge certificate;

$P$ - the probability of effective supervision;

$F$ - cost of violation punishment.

According to the question, the amount of emission certificates traded by the enterprises is given by Equations 1 and 2.

$$
\begin{gathered}
Q_{1 i}(\text { Sell })=\left\{\begin{array}{l}
L_{i}-D_{i}, L_{i} \geq D_{i}, C_{i} \geq B P \\
L_{i}, L_{i} \geq D_{i}, C_{i} \leq B P \\
L_{i}, L_{i} \leq D_{i}, C_{i} \leq B P \\
0, \text { else }
\end{array}\right. \\
Q 2 i(B \text { uy })=\left\{\begin{array}{l}
D_{i}-L_{i}, L_{i}<D_{i}, R_{i}>A P, C_{i}>B P,\left(D_{i}-L_{i}\right) A P \leq F \times p \\
0, \text { else }
\end{array}\right.
\end{gathered}
$$

Enterprise $i$ 's profit model is given by Equation 3. 


$$
\pi^{c}(i)=\left\{\begin{array}{l}
D_{i} \times R_{i}+\left(L_{i}-D_{i}\right) B P, C_{i} \geq B P, L_{i} \geq D_{i} \\
D_{i} \times R_{i}+L_{i} \times B P, C_{i}<B P \\
L_{i} \times R_{i}, L_{i}<D_{i}, R_{i}<A P \\
D_{i} \times R_{i}-\left(D_{i}-L_{i}\right) A P, L_{i}<D_{i}, R_{i} \geq A P, C_{i} \geq B P,\left(D_{i}-L_{i}\right) A P<p \times F \\
L_{i} \times R_{i}, L_{i}<D_{i}, R_{i} \geq A P, C_{i} \geq B P,\left(D_{i}-L_{i}\right) A P \geq p \times F
\end{array}\right.
$$

The market maker's profit model is given by Equation 4.

$$
\pi^{(M)}=\left\{\begin{array}{l}
\sum_{i=1}^{N} \mathrm{Q}_{1 i}(A P-B P), Q_{1 i}<Q_{2 i} \\
\sum_{i=1}^{N} \mathrm{Q}_{2 i}(A P-B P)-\sum_{i=1}^{N}\left(Q_{1 i}-Q_{2 i}\right) B P, Q_{1 i} \geq Q_{2 i}
\end{array}\right.
$$

The total system profit is given by Equation 5 .

$$
\pi^{(s)}=\sum_{i=1}^{N} Q 2 i(C i-A P)
$$

Under normal circumstances, the market price changes with the supply of the two enterprises. Since the two emission enterprises is aware that their respective production will affect the market price, that is, the market price of the product, each enterprise will carefully trade the emission permit.

Proposition 1: Under the condition of complete information, the sufficient condition for the emissions trading is that there is a non-empty emission permit price range which makes $\pi_{1} / \partial Q>0$ and ${ }^{\partial \Pi_{2}} / \partial Q>0$.

Proof: The price of the emission permit is set as. Because the rational enterprise aims to maximize the profit, considering that permit trading will cause the change buyer's the marginal emission reduction cost and the market price, the trading is not made, unless the buyer and the seller's profit increment is positive.

According to the profit function, the response curve for deriving the maximum benefit of the emission discharge enterprise is given by Equations 6 and 7 .

$$
\begin{aligned}
Q_{1} & =\frac{a-b Q_{2}-M S C_{1}-M C A_{1}}{2 b} \\
Q_{2} & =\frac{a-b Q_{1}-M S C_{2}-M C A_{2}}{2 b}
\end{aligned}
$$

The total production is given by Equation 8 .

$$
Q=Q_{1}+Q_{2}=\frac{2 a-M S C_{1}-M S C_{2}-M C A_{1}-M C A_{2}}{3 b}
$$

Cournot-Nash equilibrium production is given by Equation 9 . 


$$
Q_{1}=Q_{2}=\frac{2 a-2 M S C_{1}-M C A_{1}-M C A_{2}}{6 b}
$$

At this point, the market price of the product is given by Equation 10 .

$$
P=\frac{a+2 M S C_{1}+M C A_{1}+M C A_{2}}{3}
$$

Emission discharge enterprises are producing under balanced production. It is obvious that emission discharge enterprise 1 will obtain higher profits with lower marginal emission reduction costs. Therefore, in terms of balanced production, the enterprise 2's profit before trade is given by Equation 11 .

$$
\Pi_{2}=P Q_{2}-\int_{0}^{Q_{2}}\left(M S C_{2}+M C A_{2}\right) d t
$$

After trading, the profit of emission discharge enterprise 2 is given by Equation 12

$$
\Pi_{2} *=P^{*} Q_{2}-L_{1} P_{L}-\int_{0}^{Q_{2}} M S C_{2} d t-\int_{0}^{Q_{2} *} M C A 2 d t
$$

The conditions for the transaction are : $\Pi_{2} *-\Pi_{2} \geq 0$. Therefore, the conditions for emission discharge enterprise 2 can be given by Equation 13.

$$
P_{L} \leq \frac{\left(\Delta M C A_{1}+\Delta M C A_{2}\right) Q_{2}+3 \int_{Q_{2^{*}}}^{Q_{2}} M C A_{2} d t}{3 L_{1}}
$$

Similarly, the conditions for the buyer-- emission discharge enterprise 1 to make the trade can be given by Equation 14.

$$
P_{L} \geq \frac{\left(\Delta M C A_{1}+\Delta M C A_{2}\right) Q_{1}+3 \int_{Q^{*}}^{Q_{1}} M C A_{1} d t}{3 L_{1}}
$$

In summary, the effective conditions of the trade should satisfy Equation 15.

$$
\frac{\left(\Delta M C A_{1}+\Delta M C A_{2}\right) Q_{1}+3 \int_{Q^{*}}^{Q_{1}} M C A_{1} d t}{3 L_{1}} \leq P_{L} \leq \frac{\left(\Delta M C A_{1}+\Delta M C A_{2}\right) Q_{2}+3 \int_{Q_{2^{*}}}^{Q_{2}} M C A_{2} d t}{3 L_{1}}
$$

Because $M C A_{1} \leq M C A_{2}$, there is a non-empty price set $P_{L}$, and the trade will only occur when the price of the emission permit is in this range. In particular, when the marginal emission reduction cost of the enterprise remains unchanged in the short term, it satisfies: $M C A_{1} \leq P_{L} \leq M C A_{2}$.

In the market environment with asymmetric information, due to the uncertainty of production and operation, the lack of understanding of the needs of the trading parties, etc., the emission discharge enterprises often consider the question of when to buy and 
sell, how much to buy and sell, which brings the emissions trading Uncertainty. But at this time, if there is a seller in the market, it can be seen that it provides clear information to the market, because the appearance of selling often means the certainty of the remaining. Conversely, the information conveyed by the buyer is often not clear enough, because the existence of uncertainty tends to increase the demand of the enterprise, resulting in more purchases in the market than real demand. Therefore, the emergence of the seller is a key factor in determining the efficiency of the information asymmetry market.

Proposition 2: Under the asymmetric information environment, the trading volume of emission rights depends on the sales volume of the enterprise.

Proof: It is assumed that under the condition that the price range satisfies the trade occurrence, the probability of the emission discharge enterprise 1 selling the permit is: the probability of not selling is. The smaller the probability value, the stronger the uncertainty of the emission discharge enterprise 1 selling the emission permit. In this regard, the emission discharge enterprise 2 has two strategies: buy, not buy, the strategy matrix is shown in the following Table 1.

Table 1. Strategic matrix of sewage enterprises

\begin{tabular}{c|c|c}
\hline & Sell $(p)$ & Not sell $(1-p)$ \\
\hline \multirow{3}{*}{ Buy } & $P^{*} Q_{1}+L_{1} P_{L}-\int_{0}^{Q_{1}} M S C_{1} d t$ & $P Q_{1}-\int_{0}^{Q_{1}} M S C_{1} d t-\int_{0}^{Q_{1 *}^{*}} M S C_{1} d t$, \\
& $P^{*} Q_{2}-L_{1} P_{L}-\int_{0}^{Q_{2}} M S C_{2} d t-\int_{0}^{Q_{2^{*}}} M C A_{2} d t$ & $P Q_{2}-\int_{0}^{Q_{2}} M S C_{2} d t-\int_{0}^{Q_{2}} M C A_{2} d t$ \\
\hline \multirow{3}{*}{ Not buy } & $P Q_{1}-\int_{0}^{Q_{1}}\left(M S C_{1}+M C A_{1}\right) d t$ & $P Q_{1}-\int_{0}^{Q_{1}} M S C_{1} d t-\int_{0}^{Q_{1}^{*}} M S C_{1} d t$, \\
& $P Q_{2}-\int_{0}^{Q_{2}}\left(M S C_{2}+M C A_{2}\right) d t$ & $P Q_{2}-\int_{0}^{Q_{2}} M S C_{2} d t-\int_{0}^{Q_{2}} M C A_{2} d t$ \\
\hline
\end{tabular}

Under the two strategies, the expected value functions of the emission discharge enterprises 2 are Equations 16 and 17.

$$
\begin{gathered}
E\left(\Pi_{2 B_{\mathrm{uy}}}\right)=p\left(P^{*} Q_{2}-L_{1} P_{L}-\int_{0}^{Q_{2}} M S C_{2} d t-\int_{0}^{Q_{2}^{*}} M C_{2} d t\right)+(1-p)\left(P Q_{2}-\int_{0}^{Q_{2}} M S C_{2} d t-\int_{0}^{Q_{2}} M C A_{2} d t\right) \\
E\left(\Pi_{2 \text { Notbuy }}=P Q_{2}-\int_{0}^{Q_{2}}\left(M S C_{2}+M C A_{2}\right) d t\right.
\end{gathered}
$$

According to the expected value decision rule, the conditions for the trade should satisfy Equation 18.

$$
E\left(\Pi_{2 \text { Buy }}\right) \geq E\left(\Pi_{2 \text { Notbuy }}\right)
$$

Inferred that the price generated by the trade is given by Equation 19.

$$
P_{L} \leq \frac{\left(M C A_{2} *-M C A_{2}\right) Q_{2}+3 \int_{Q^{*}}^{Q_{2}} M C A_{2} d t}{3 L_{1}}
$$


This price condition is exactly the same as the previous buying condition, that is, as long as the price is in the tradable range, the emission discharge enterprise 2 will certainly buy the emission permit, because the purchasing strategy is always profitable for the emission discharge enterprise 2. Then the key factor restricting the sale and purchase is the probability of the sales of the emission discharge enterprise 1 . The greater the probability that the emission discharge enterprise 1 sells, the easier the trade will be generated, conversely, the less likely the trade is. That is: the amount of sales of emission permit is a key factor in determining the volume of emissions trading.

According to Proposition 1 and Proposition 2, whether a market mechanism is effective depends on whether it can make the price in a tradable range and how to form a seller. Based on this analysis, this study compares and analyzes the difference between the market maker's quotation transaction and the current implementation of the emission trading price and the seller's formation mechanism in China.

\section{Data and simulation analysis}

For the sake of clarity, it is assumed that there are two emission discharge enterprises in the same region that use the same technology to produce homogeneous products, which have the same marginal social cost $(M S C)$. In terms of quantity, the marginal social cost is equal to the sum of the marginal cost of the production of the emission discharge enterprise $(M C)$ and the marginal external cost of emission caused by the environment $(M E C): M S C=M C+M E C$. Under the conditions of the scale of production, the proportion of input factors, and the fixed level of technology, for the enterprises, the marginal social cost is tilted upwards, because with the increase in production of emission discharge enterprise, the marginal cost of production rises, and with the amount of emission Increase, the harm to the environment also rises. However, due to the different emission reduction technologies adopted, the marginal emission reduction costs $(M C A)$ of the two enterprises are different, and they are respectively $M C A_{1}$ and $M C A_{2}$. In the short-term, due to the fixed level of emission reduction, the marginal emission reduction cost of emission reduction enterprises should be tilted downwards, because enterprises need to install specific emission reduction equipment when they reduce emissions. When the emission reduction is small, the unit cost will be higher. When the emission reduction is high, the unit cost is reduced accordingly.

It is assumed that the emission discharge enterprises are producing with the goal of maximizing profits, and the target yields of the two enterprises maximizing profits are respectively, and at the same time, because the products are homogeneous, the emission discharge enterprises have the same product demand curve.

Let product price as $P=a-b Q, Q$ is the total production of emission discharge enterprise 1 and 2, that is $Q=Q_{1}+Q_{2}$. Then emission discharge enterprise 1's expected income function is Equation 20.

$$
\operatorname{Max} \Pi_{1}=P Q_{1}-\int_{0}^{Q_{1}}\left(M S C_{1}+M C A_{1}\right) d t
$$

Then emission discharge enterprise 2's expected income function is Equation 21.

$$
\operatorname{Max} \Pi_{2}=P Q_{2}-\int_{0}^{Q_{2}}\left(M S C_{2}+M C A_{2}\right) d t
$$


According to the above mathematical model hypothesis, after compiling and running the Fables program, a graphical interface as shown in Figure 1 will be formed. The parameters of the model are displayed in the dialog box on the left side of the interface, which includes the emission reduction costs set in the previous section. For parameter values such as asking price and bid, the interface box on the right side of the graph is the area showing the result after the program runs.

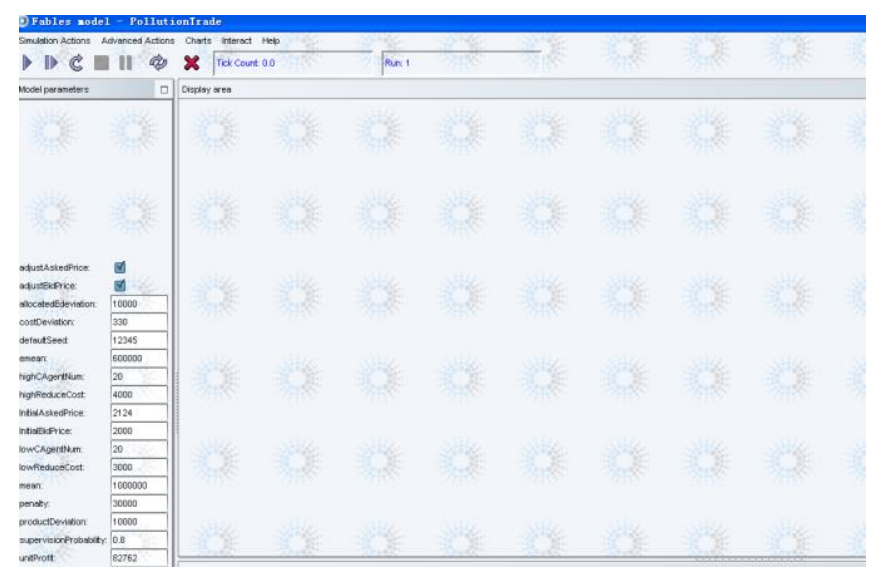

Figure 1. Running interface of program

According to the research needs, this study sets four research variables: spread, trading volume, market maker profit, and profit of emission discharge enterprise. The time period is an important factor in the reliability of the reaction simulation results. Therefore, this paper observes the stability of the simulation run for 50 cycles and analyzes the reliability of the indicators. The simulation results are shown in Figure 2.

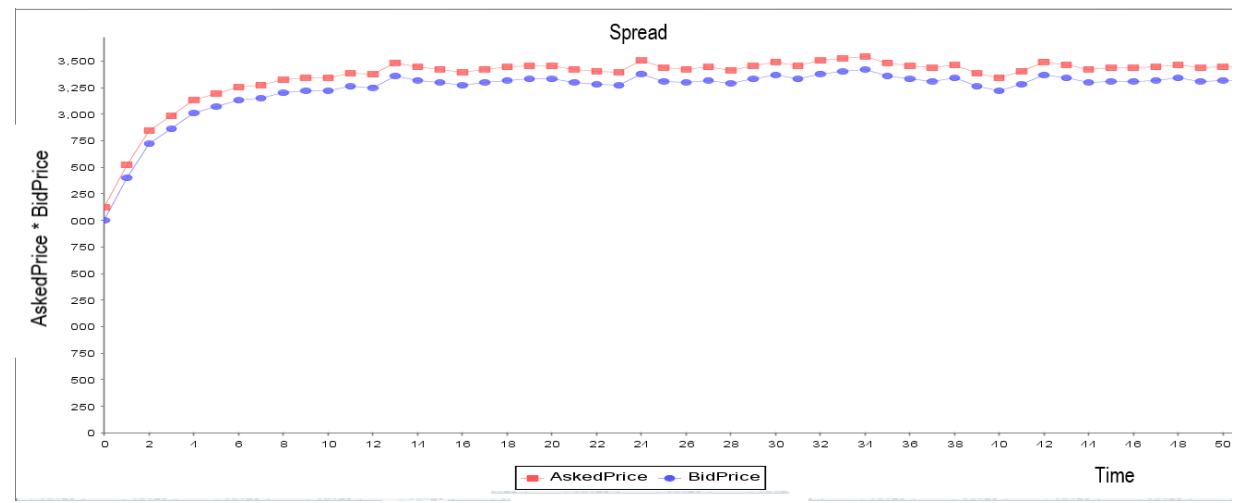

Figure 2. Simulation diagram of the market maker quotation

The simulation results of the market maker's quotation in Figure 2 show that during the 50 cycles of operation, the market maker's quotation and the trend of the price difference are relatively stable, and the volatility of the quotation is small. After about 50 cycles of operation, the quotation increased from the bid of 2,000 yuan/ton and the asking price of 2,124 yuan/ton to the bid of about 3,250 yuan/ton and the asking price of 3,500 yuan/ton, and then stabilized. Through the quote of the market maker, realization of market price discovery mechanism can be enhanced. 
The simulation results of the market trading volume in Figure 3 show that the average market buying and selling volume fluctuates around 6500 as the axis, and the pattern is in good coincidence. This shows that the buyer and the seller are in the same trend, and the market trade are very active. According to the average purchase and sales volume of 6,500, the total trade volume of each period can reach 260,000 units, calculated according to the total allocation of 600,000 . The trade ratio is as high as $43 \%$, which will optimize the rational allocation of emission permits. However, as the average fluctuation of the sales volume is small, the volatility of the purchase volume is relatively large, indicating that the large fluctuations in the purchase volume will increase the uncertainty of the market demand for emission permits. as the market organizer. the market maker has a need to have a certain amount of reserves to deal with market risks.

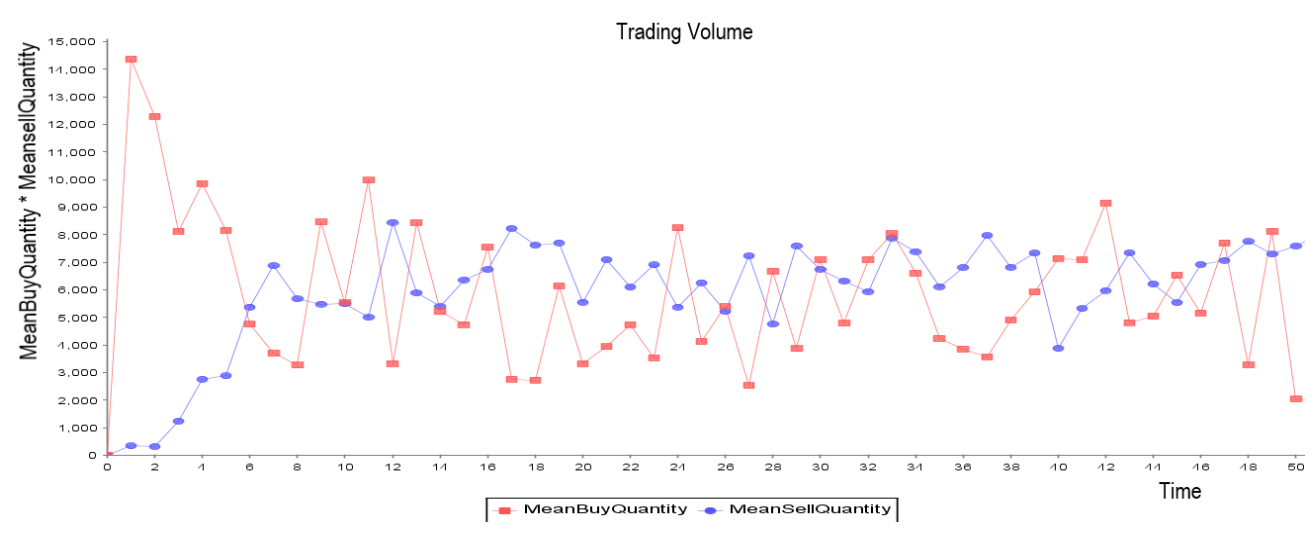

Figure 3. Simulation diagram of trading volume

As shown in the simulation results of the market maker's profit in Figure 4, in the 50 cycles of operation, the profit of the market maker mainly fluctuates between -5 million and -17.5 million, and the profit fluctuation is large. There are two main reasons for the phenomenon: First, the emission permit is set as not storable, which means that the current permit cannot be used for the next trade. This will bring storage costs and maturity loss risk to the market makers; second, the volume of trading in the company's buying volume fluctuates greatly, which increases the risk of market maker trading.

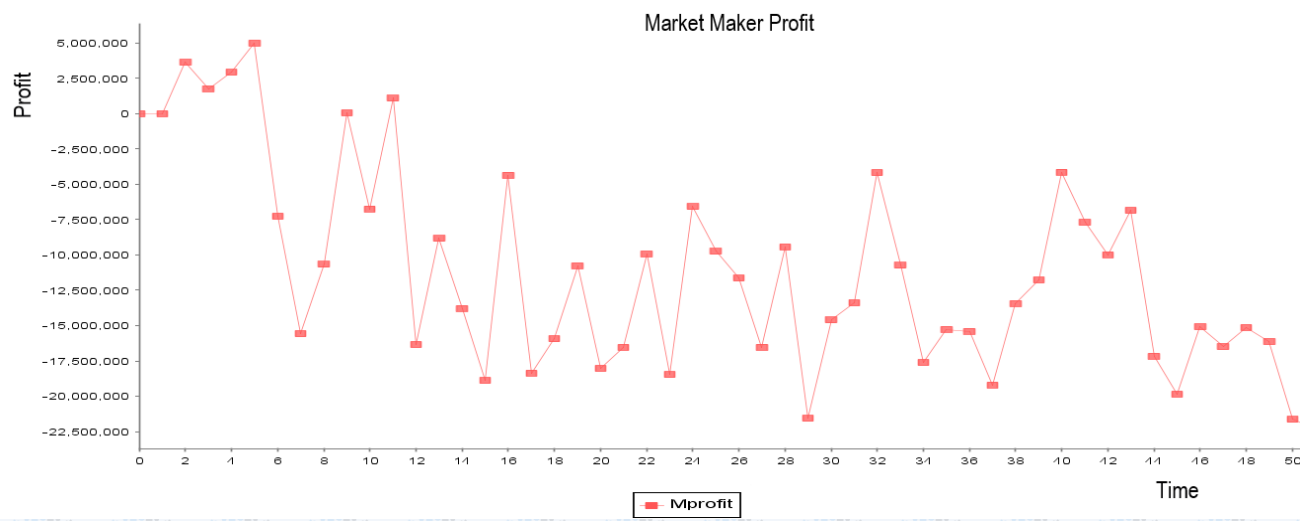

Figure 4. Simulation diagram of the market maker profit 
Although the previous simulation results show that the market maker's profit is negative, Figure 5 shows that the entire emissions trading system has positive returns, and the return value fluctuates between mainly 1 million and 4 million. This indicates that in the case where storage is not allowed, although the market maker suffers a certain loss, the increase in the profit of the emission discharge enterprises and the saving of the emission reduction cost can make up for this loss. Therefore, a comprehensive analysis of the above simulation results shows that market transactions involving market makers increase market efficiency.

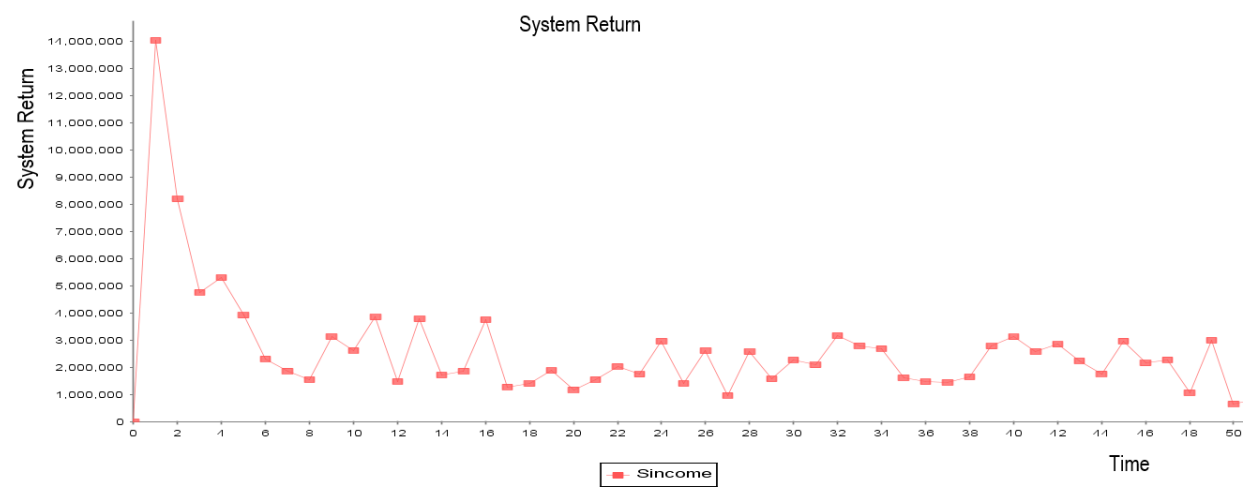

Figure 5. Simulation diagram of system return

\section{Results and discussion}

In order to understand the performance of the emissions trading market under different market conditions, and to formulate corresponding institutional measures to ensure the operation of the market maker trading market system, this study analyzes the changes in market quotations, system returns and other indicators by changing certain market parameter values and features.

\section{The impact of market demand variance on market maker transactions}

When setting the initial value of the simulation, the variance of the market demand variable and the emission right distribution variable is small. This is suitable for the steel industry, which has a small difference between enterprises and a stable market environment. However, in certain industrial environments, or in certain specific environments, market demand changes more severely, and smaller demand variances do not reflect this market change. In addition, in the current allocation of emission rights, the distribution of emission rights often has a higher correlation with the market demand and production volume of the enterprise, and the presence of market power will further aggravate the inequality of the distribution of emission rights.

In order to make the research results more obvious, this study increases the standard deviation of market demand parameters to 10,000 , and the standard deviation of emission allocation parameters to 10,000 , thus to compare the performance of market makers in different market environments. The simulation results are shown in Figure 6.

Figure 6 shows that during the 50 cycles of operation, the volatility of the market maker's quotation increased after the variance increased, although the main quotation range is still concentrated around 3250. The simulation results show that the market 
maker's quotation level and spread is greatly affected by the balance of market demand and emission permit allocation.

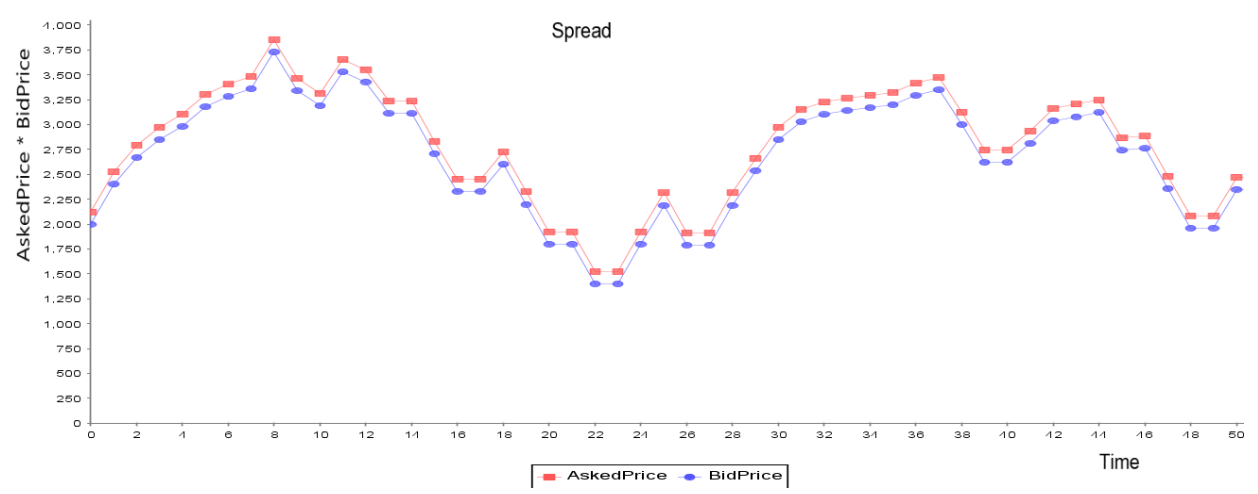

Figure 6. Simulation diagram of market maker quotation after increasing the variance

Figure 7 shows that in a drastic market and in the presence of market power, the market's buying and selling volume still have a good coincidence, but the market's trading volume has slightly decreased, and the sales volume is more discrete. The simulation results show that the market trade are in good condition, but the difference between the sales volume and the purchase volume of the market trade becomes larger.

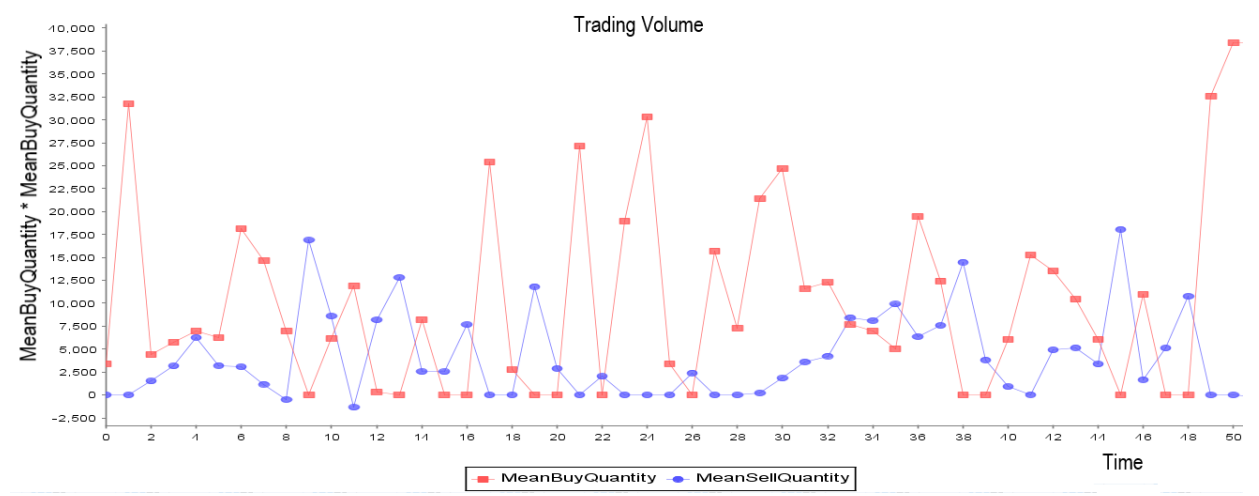

Figure 7. Simulation diagram of trading volume after increasing the variance

Figure 8 shows that during the 50 cycles of operation, due to the large fluctuations in the amount of purchases and sales in the market, the profit of market makers also showed strong volatility. But the market makers' profit in some cycles has positive values, which indicates that in the severe market environment, the distribution method of the different emission permits will increase the profit of the market maker.

Figure 9 shows that in the 50 cycles of operation, the system returns are nonnegative, and the mean and fluctuation of system benefits are high. The simulation results show that the market demand is uncertain and there is a serious distribution bias. Using market maker transactions can significantly increase the revenue of the entire trading system.

From above simulation analysis it can be seen that under the severe market and the large difference in the market distribution of emission permits, the quotation of market 
makers is relatively higher, the system transactions will still maintain a high level, and the system returns are higher. Therefore, it is more suitable to use the market maker market transaction in this environment.

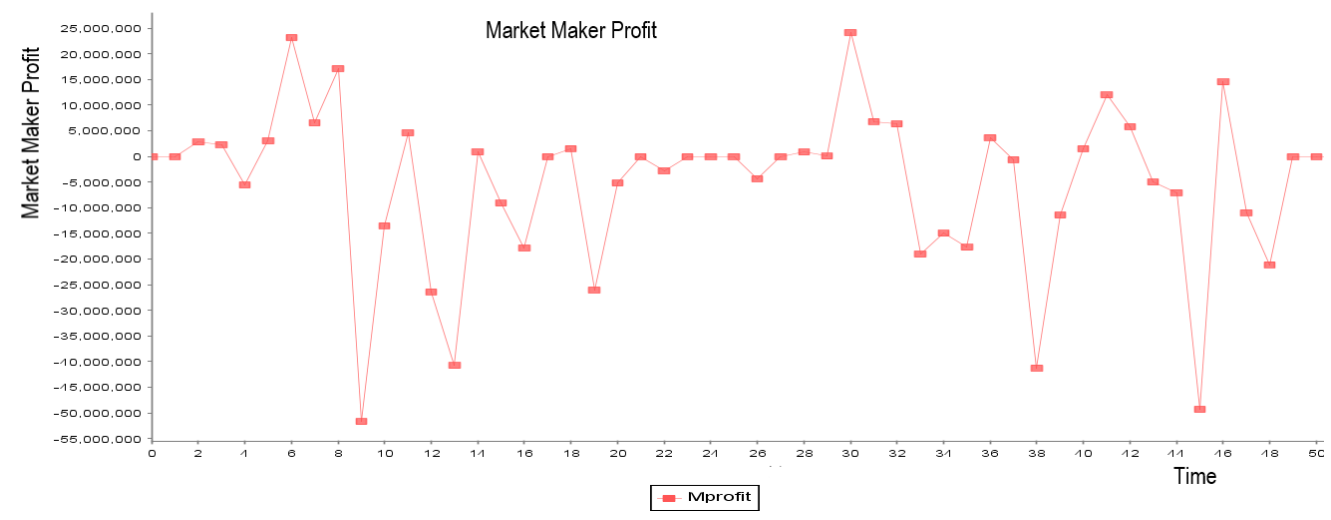

Figure 8. Simulation diagram of market maker profit after increasing the variance

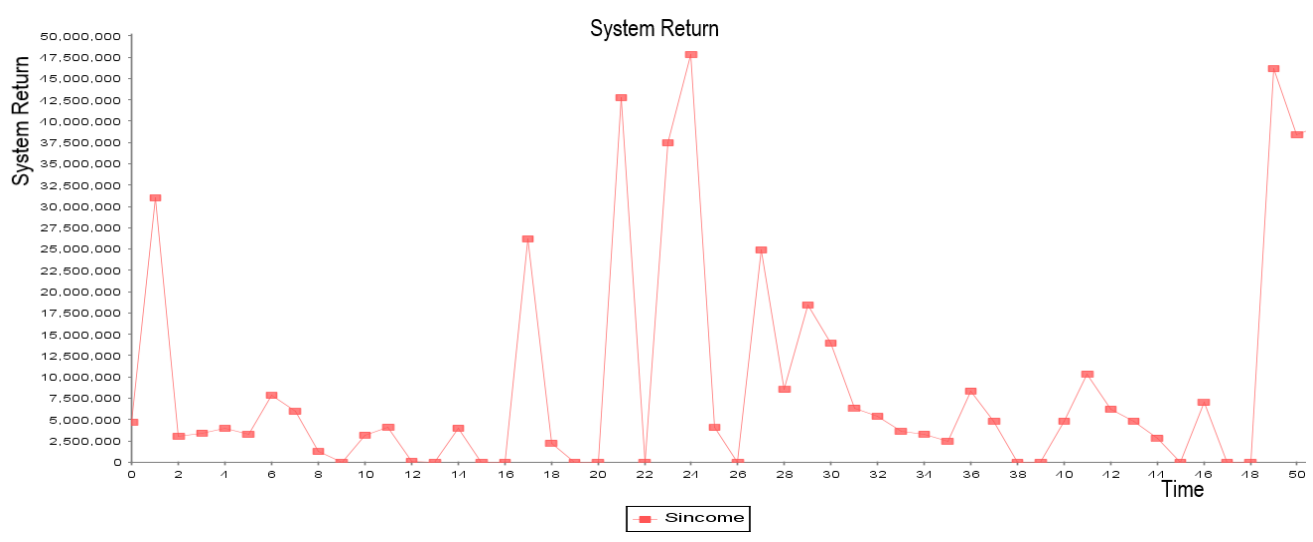

Figure 9. Simulation diagram of system return profit after increasing the variance

\section{The effect of spreads on market maker trading}

In market maker trading, the price difference is an important factor that restricts the market price and the profit of the market trading entity. In the current financial market, many countries and regions have a clear limit on the price difference of market makers. Therefore, this paper adjusts the spread to compare the impact of the spread on the market for emissions trading.

As shown in Figures 10 and 11, the change in the spread during the 50 cycles of operation did not result in large fluctuations in the quoted price of the market maker. However, under the $20 \%$ spread, the asking price of the market maker rose to about 3,750 , and under the $40 \%$ spread, the asking price of the market maker rose to about 4,250. Therefore, the simulation results show that the change in the spread does not change the trend of the quote. However, the change in the price difference will change the absolute value of the market maker's quotation, thus affecting the supply and demand relationship of the market. 


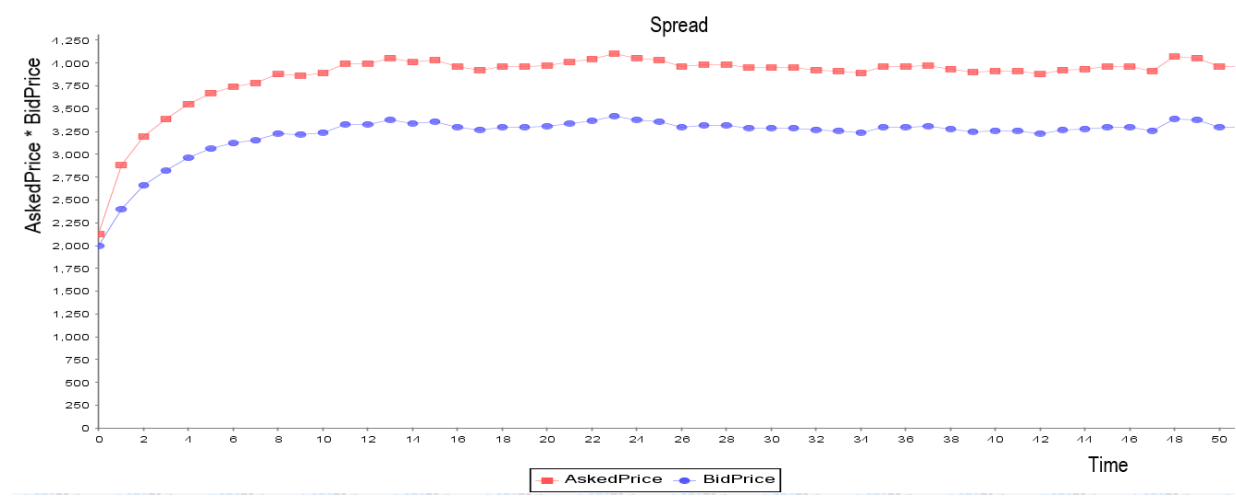

Figure 10. Simulation diagram of market maker quotation under $20 \%$ spread

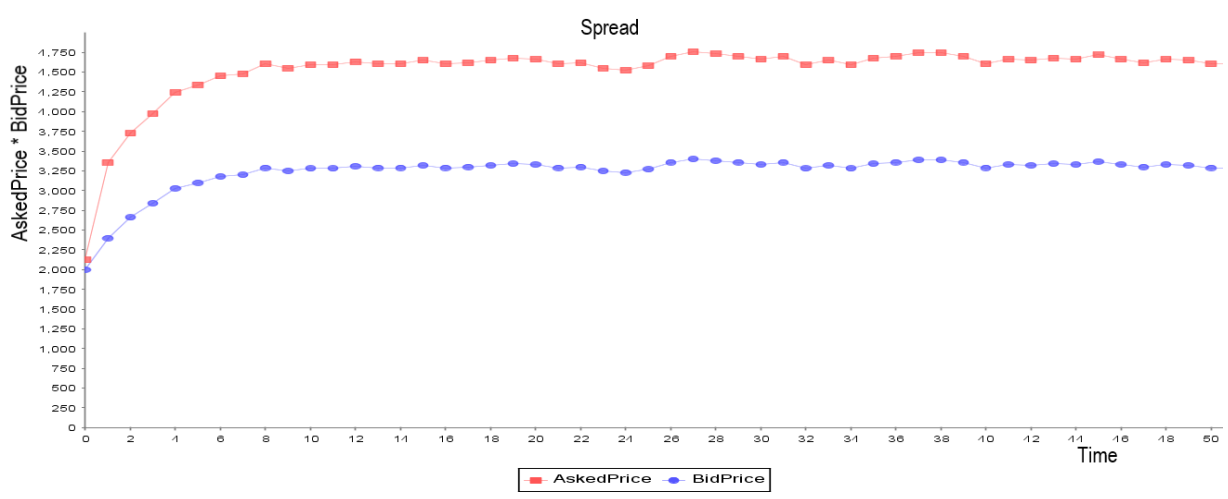

Figure 11. Simulation diagram of market maker quotation under $40 \%$ spread

As shown in Figures 12 and 13, the market's sales volume and purchase volume coincidence are better under different price differences. However, in comparison, under the $40 \%$ spread, the market transaction volume is relatively high, indicating that the higher the price difference, the higher the uncertainty of market transactions.

As shown in Figures 14 and 15, although the spread of the market maker's offer has increased, the market maker's profit is still negative, and both fluctuate with an axis of 12.5 million. This shows that despite the increase in the spread, the increase in the spread has changed the supply and demand relationship, resulting in fewer purchases. Therefore, the increase in market maker inventory reduces the profit of market makers.

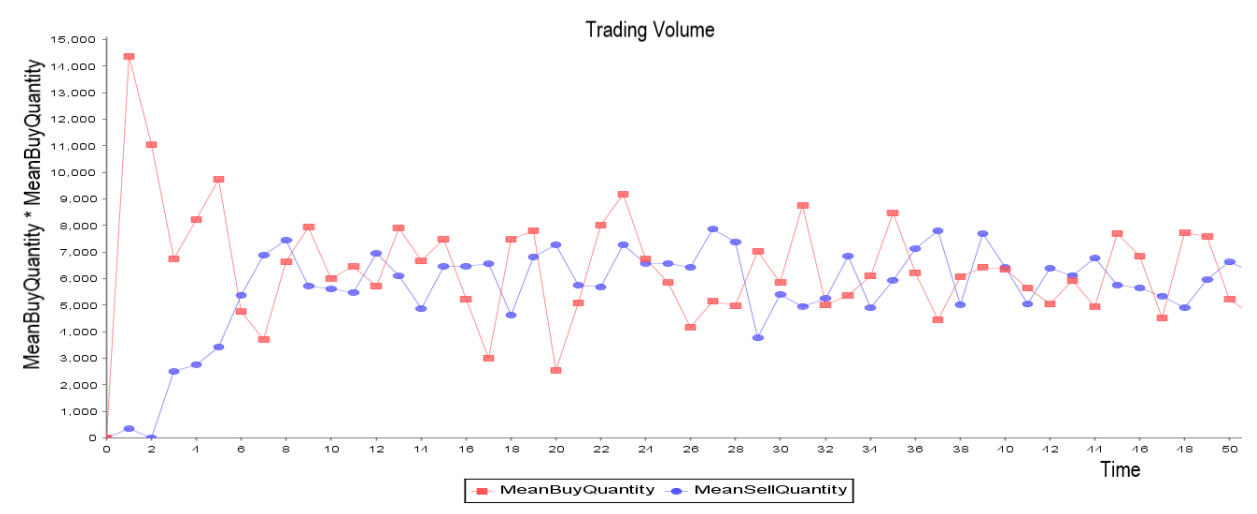

Figure 12. Simulation diagram of trading volume under $20 \%$ spread 


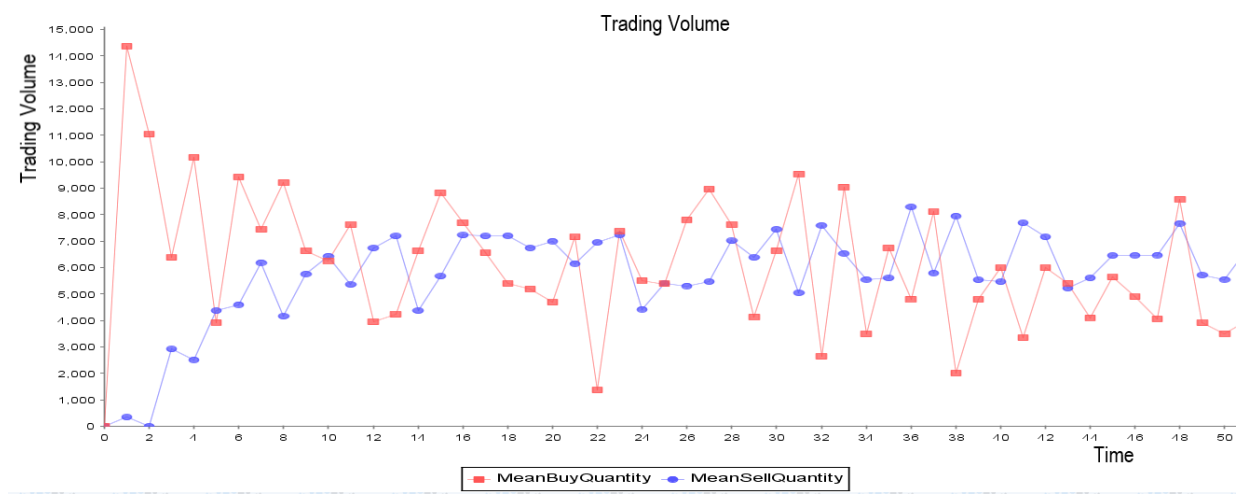

Figure 13. Simulation diagram of trading volume under $40 \%$ spread

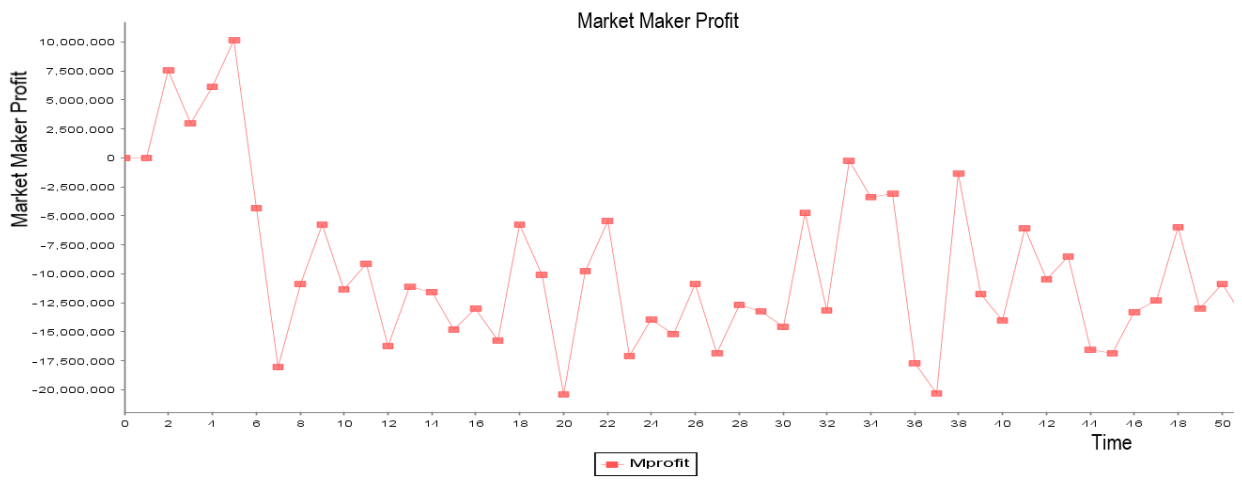

Figure 14. Simulation diagram of market maker profit under $20 \%$ spread

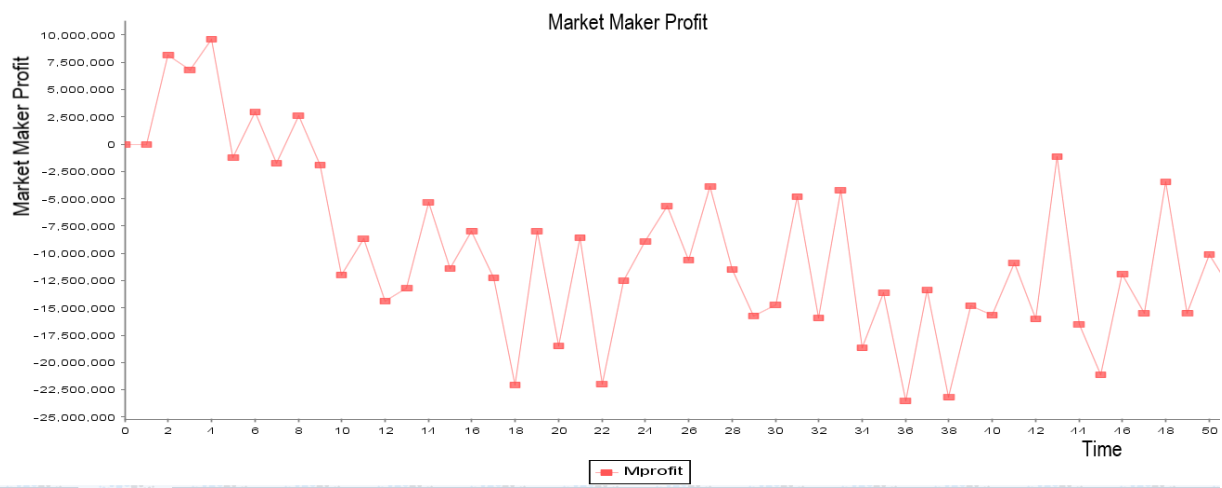

Figure 15. Simulation diagram of market maker profit under $40 \%$ spread

As shown in Figures 16 and 17, in the 50 operating cycles, the system benefits under the $20 \%$ spread have fluctuated near the edge of zero, which has been greatly reduced compared to the previous system benefits. Under the $40 \%$ spread, the system returns are all negative, and the average is large, reaching -1 million.

Based on the above analysis, the increase in the spread will reduce the system revenue. Therefore, the market price should be limited in the market maker trading market. According to the analysis of the simulation results, the spread should be controlled within $20 \%$. 


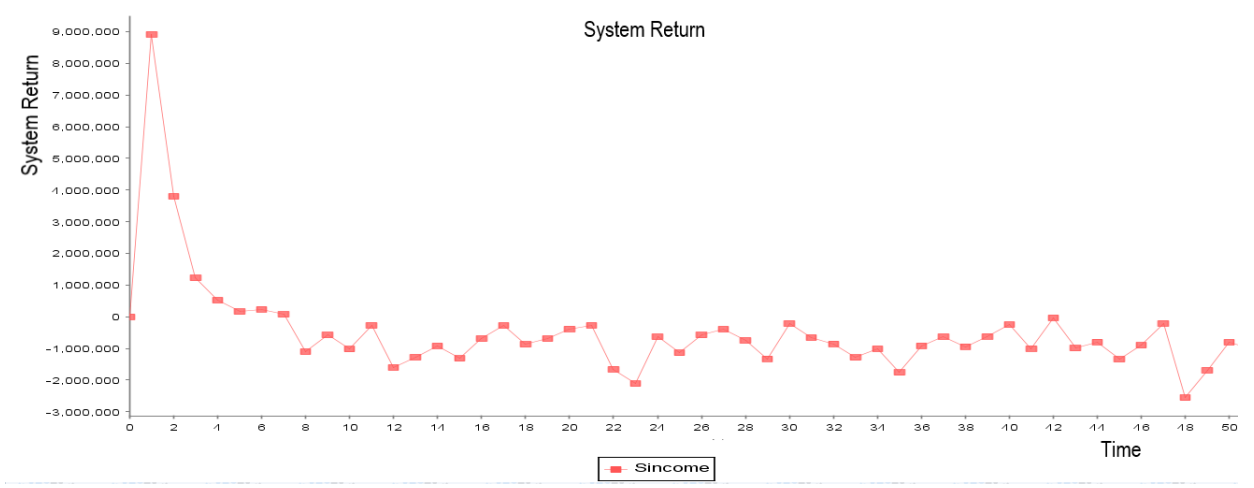

Figure 16. Simulation diagram of system return under $20 \%$ spread

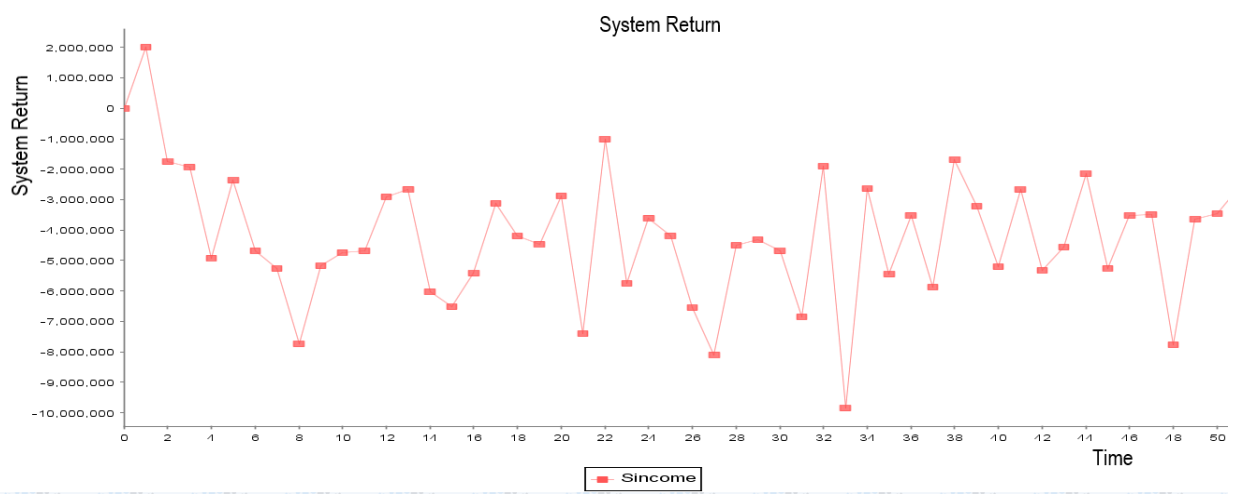

Figure 17. Simulation diagram of system return under $40 \%$ spread

\section{Conclusions}

In the long run, the emissions trading market is in a dynamic system consisting of market makers, emission discharge enterprises, and government. In this paper, we use the simulation experiment method to simulate the operation mode of the emissions trading complex system, and draw the following main conclusions:

First, market maker trading is applicable to a variety of market environments, and can improve the efficiency of the emissions trading system. The simulation results show that regardless of whether the market yield of the products produced by the enterprise is higher or lower, whether it is fluctuating violently or mildly, whether there is market power in the emission permit market, whether the competition of the emission discharge enterprises is fierce, market maker transactions can make Emissions trading volume at a high level, and system revenue is positive.

Second, even if the market for enterprise products fluctuates drastically and there is a large difference in the initial distribution of warrants, market maker transactions are still suitable. Although the quotes of market makers are higher, the system returns are higher.

Third, the increase in the number of emission discharge enterprises will affect the quotation level of market makers, but will not change the trend of market makers' quotations. 
Fourth, the increase in the spread will reduce the system revenue, and the market price of the market maker should be limited in the emissions trading market. According to the simulation results, the spread should be controlled within $20 \%$.

Fifth, the adverse environment caused by the introduction of new products, the violent market fluctuations, and the rise of raw materials for products does not hinder the smooth conduct of emissions trading. The market makers can lower the quotation to balance supply and demand, so that the system returns are positive.

In future research, the assumptions could be relaxed in the proposed problem settings to observe their effects on the solutions, so that results could serve the needs of the real world. On the other hand, it is necessary to conduct an study of the behavioral rules of all parties involved in, which would provide a better solution for the parties. Finally, to improve the accuracy of the simulation results, some sophisticated methods can be used to set market demand parameters and emission allocation parameters, in which the set of parameters could be needed.

Acknowledgements. This paper is supported by MOE (Ministry of Education in China) Project of Humanities and Social Sciences (19YJC630043), National Natural Science Foundation of China (J1824031), the Fundamental Research Funds for the Central Universities (B18RC00070) and Beijing Municipal Bureau of Economy and Information Technology Funds (T17M00070). We appreciate their support very much.

\section{REFERENCES}

[1] Bloomfield, R., O’Hara, M. (2000): Can transparent markets survive? - Journal of Financial Economics 55(3): 425-59.

[2] Bondarenko, O. (2001): Competing market makers, liquidity provision, and bid-ask spreads. - Journal of Financial Markets 4(3): 269-308.

[3] Calcagno, R., Lovo, S. (2006): Bid-ask price competition with asymmetric information between market makers. - Review of Economic Studies 73(2): 329-355.

[4] Demsetz, H. (1968): The cost of transaction. - Quarterly Journal of Economics 82(1): 3353.

[5] Du, J., Li, Q., Qiao, F., Yu, L. (2018): Estimation of vehicle emission on mainline freeway under isolated and integrated ramp metering strategies. - Environmental Engineering and Management Journal 17(5): 1237-1248.

[6] Flood, M. D., Huisman, R., Koedijk, K. G. (1999): Quote disclosure and price discovery in multiple-dealer financial markets. - The review of Financial Studies 12(1): 37-59.

[7] Glosten, L. R., Milgrom, P. R. (1985): Bid, ask and transaction prices in a specialist market with heterogeneously informed traders. - Journal of Financial Economics 14(1): 71-100.

[8] Gong, D., Liu, S., Tang, M., Ren, L., Liu, J. (2018): Revenue sharing or profit sharing? An internet production perspective. - Advances in Production Engineering \& Management 13(1): 81-92.

[9] Kyle, A. S. (1985): Continuous auction and insider trading. - Econometrica 53(6): 13151335.

[10] Kedia, S., Zhou, X. (2011): Local market makers, liquidity and market quality. - Journal of Financial Markets 14(4): 540-567.

[11] Miao, J. A. (2006): Search model of centralized and decentralized trade. - Review of Economic Dynamics 9: 68-92.

[12] Shen, P., Starr, R. M. (2002): Market-makers' supply and pricing of financial market liquidity. - Economics Letters 76(1): 53-58. 
[13] Tarun, C., Richard, R. (2001): Market liquidity and trade activity. - The Journal of Finance 56(2): 501-530.

[14] Zhu, M., Chiarella, C., He, X. Z., Wang, D. (2009): Does the market maker stabilize the market? - Physica A: Statistical Mechanics and its Applications 388(15-16): 3164-3180.

[15] Zhang, Y. P., Li, Y. (2011): A probe into the market maker system of China's stock market based on the analysis of the overall welfare and transaction cost of market participants under asymmetric information. - On Economic Problems (9): 91-95. 